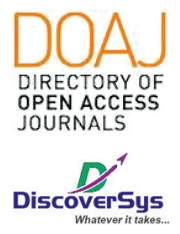

Published by DiscoverSys

\section{Hubungan antara nyeri punggung dan penggunaan tas punggung pada siswa di SDN 23 Dangin Puri Denpasar}

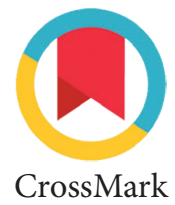

\author{
Kadek Puja Asmara Miranda, ${ }^{1 *}$ Sri Yenni Trisnawati, ${ }^{2}$ Ida Ayu Sri Wijayanti ${ }^{2}$
}

\title{
ABSTRACT
}

Background: Back pain is the third most common event after selfagia and migraine. The use of the backpack is one of the factors causing back pain. The aim of this study was to find out the correlation between back pain and backpack use.

Methods: Analytical research with cross sectional method and using primary data. Data collection was carried out at SDN 23 Dangin Puri Denpasar from October to December 2018.
Results: The subjects of the study consisted of $54 \%$ female and $46 \%$ male. Age range in samples ranges from 9 to 12 years. Male and female sex did not have a significant effect on complaints of back pain. Positive correlation between back pain and backpack use $(p=0.004)$. Backpack weight has a correlation with back pain.

Conclusions: Back pain has a positive correlation with the use of backpack

Keywords: back pain, backpack

Cite This Article: Miranda, K.P.A., Trisnawati, S.Y., Wijayanti, I.A.S. 2019. Hubungan antara nyeri punggung dan penggunaan tas punggung pada siswa di SDN 23 Dangin Puri Denpasar. Intisari Sains Medis 10(3): 848-851. D0l: 10.15562/ism.v10i3.504

\section{ABSTRAK}

Latar Belakang: Nyeri punggung merupakan kejadian terbanyak ketiga setelah selfagia dan migraine. Penggunaan tas punggung adalah salah satu factor penyebab nyeri punggung. Tujuan studi ini adalah mengetahui hubungan antara nyeri punggung dan penggunaan tas punggung.

Metode: penelitian analitik dengan metode cross sectional (potong lintang) dan menggunakan data primer. Pengambilan data dilakukan di SD N 23 Dangin Puri Denpasar dari Oktober sampai dengan Desember 2018.
Hasil: Subjek penelitian terdiri atas 54\% perempuan dan 46\% laki - laki. Jangkauan usia pada sampel berkisar antara 9 hingga 12 tahun. Jenis kelamin laki - laki dan perempuan tidak memiliki perbedaan yang signifikan terhadap keluhan nyeri punggung. Korelasi positif antara nyeri punggung dan penggunaan tas punggung $(p=0.004)$. berat tas memiliki hubungan dengan nyeri punggung.

Simpulan: nyeri punggung ada korelasi positif dengan penggunaan tas punggung.
1Program Studi Pendidikan Dokter Fakultas Kedokteran Universitas Udayana

${ }^{2}$ Departemen/SMF Neurologi, Fakultas Kedokteran Universitas Udayana

\section{*Korespondensi:}

Kadek Puja Asmara Miranda, Program Studi Pendidikan Dokter Fakultas Kedokteran Universitas Udayana asmaramiranda16@gmail.com

Diterima: 12-04-2019

Disetujui: 24-11-2019

Diterbitkan: 01-12-2019
Kata kunci: nyeri punggung, tas punggung

Cite Pasal Ini: Miranda, K.P.A., Trisnawati, S.Y., Wijayanti, I.A.S. 2019. Hubungan antara nyeri punggung dan penggunaan tas punggung pada siswa di SDN 23 Dangin Puri Denpasar. Intisari Sains Medis 10(3): 848-851. D0I: 10.15562/ism.v10i3.504

\section{PENDAHULUAN}

Sekolah merupakan tempat yang akan dituju oleh sebagian besar siswa untuk memperoleh pendidikan. Hal penunjang yang diperlukan untuk masuk sekolah adalah buku pelajaran. Tidak heran buku - buku pelajaran untuk siswa sangatlah penting dan harus dibawa setiap mengikuti pelajaran disekolah. Tas sekolah sangat diperlukan untuk membantu siswa dalam membawa buku - buku tersebut. Dewasa ini siswa lebih memilih untuk menggunakan tas punggung dalam membawa buku pelajaran. Buku pelajaran yang dibawa pun bisa dibilang tidak sedikit karena semakin banyaknya pembelajaran untuk siswa. Ada beberapa penelitian mengatakan bahwa sebagian besar siswa membawa beban pada tas punggung 10\% lebih berat dibandingkan dengan massa tubuhnya. Penggunaan tas punggung yang berat setiap hari ini akan menyebabkan masalah pada kesehatan anak. ${ }^{1}$ Nyeri Punggung dapat disebabkan oleh berbagai sebab seperti, postur tubuh yang buruk, trauma dan salah satunya adalah mengangkat beban berat dalam jangka waktu yang terlalu lama. ${ }^{2}$ Beban yang berat tersebut dapat mengakibatkan nyeri pada punggung dan leher si anak dan juga tekanan fisik secara terus - menerus pada punggung dan bahu dapat mengganggu kesehatan pada anak. Hal 
tersebut disebabkan karena anak sekolah dasar tersebut masih terlalu dini untuk membawa tas punggung yang sangat berat.

Pada umur 8-15 tahun merupakan masa dimana anak - anak tumbuh dan berkembang dengan pesat. Namun, dengan tambahan beban pada bagian belakangnya akan membuat pertumbuhan anak terhambat. Wilmarth, anggota spesialis kedokteran

Tabel 1 Karakteristik Subjek Penelitian

\begin{tabular}{lcc}
\hline Karakteristik & N & Persentase (\%) \\
\hline Kelompok Usia & 17 & 34 \\
$9-10$ tahun & 33 & 66 \\
$11-12$ tahun & & \\
Tingkat Pendidikan & 10 & 20 \\
4 SD & 20 & 40 \\
5 SD & 20 & 40 \\
6 SD & & 54 \\
Jenis Kelamin & 27 & 46 \\
Laki-laki & 23 & 28 \\
Perempuan & & 72 \\
Berat Tas & 14 & \\
$<3$ kg & 36 & 94 \\
$>3$ kg & & 6 \\
Keluhan Nyeri Punggung & 47 & \\
Ada & 3 & \\
Tidak Ada & 98 & \\
Klasifikasi Nyeri Punggung & & \\
Nyeri Punggung Atas & & \\
Nyeri Punggung Bawah & & \\
\hline
\end{tabular}

Tabel 2 Karakteristik Subjek dengan Nyeri Punggung Berdasarkan Usia

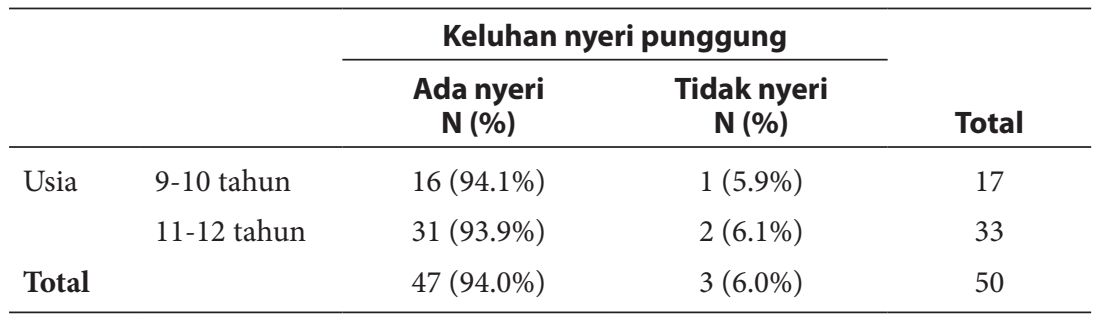

Tabel 3 Karakteristik Subjek dengan Nyeri Punggung Berdasarkan Tingkat Pendidikan

\begin{tabular}{lcccc}
\hline & & \multicolumn{2}{c}{ Keluhan nyeri punggung } & \\
\cline { 3 - 4 } & & $\begin{array}{c}\text { Ada nyeri } \\
\mathbf{N}(\%)\end{array}$ & $\begin{array}{c}\text { Tidak nyeri } \\
\mathbf{N}(\%)\end{array}$ & Total \\
\hline Tingkat pendidikan & $4 \mathrm{SD}$ & $10(100 \%)$ & 0 & 10 \\
& $5 \mathrm{SD}$ & $18(90 \%)$ & $2(10 \%)$ & 20 \\
& $6 \mathrm{SD}$ & $19(95 \%)$ & $1(5 \%)$ & 20 \\
Total & & $47(94 \%)$ & $3(6 \%)$ & 50 \\
\hline
\end{tabular}

pada bidang olahraga mempercayai bahwa tas punggung yang berat dapat mengakibatkan nyeri pada bagian punggung. Berdasarkan Amerika Chiropractic Association menyatakan bahwa siswa sekolah dasar tidak seharusnya membawa beban lebih dari $10 \%$ lebih berat dibandingkan massa badan mereka. ${ }^{3}$ Maka dari itu sangat diperlukan pengertian dari pihak sekolah agar siswa sekolah dasar bisa membawa buku pelajaran yang lebih sedikit namun sangat diutamakan dibandingkan harus membawa semua buku pelajaran yang beratnya bisa hampir $5 \mathrm{~kg}$ untuk satu siswa. Kesehatan anak sangatlah diutamakan agar tidak menghambat pertumbuhan dan perkembangan mereka.

\section{METODE}

Penelitian ini adalah penelitian analitik dengan metode cross sectional (potong lintang). Pengambilan data dilakukan di SD N 23 Dangin Puri Denpasar dari Oktober sampai dengan Desember 2018.

Subyek penelitian adalah siswa dan siswi sekolah dasar kelas 4-6 SD di Sekolah Dasar Negeri 23 Dangin Puri Denpasar pada tahun ajaran 2017/2018. Kriteria inklusi adalah Pengguna tas punggung ke sekolah dan bersedia menjadi responden. Kriteria ekslusi adalah subjek menolak untuk berpartisipasi subjek tidak dapat mengikuti proses pengisian kuisioner dan wawancara karena suatu alasan tertentu.

Pengambilan sampel dilakukan dengan menggunakan metode consecutive sampling. Penelitian ini menggunakan data primer, dengan daftar pertanyaan dalam bentuk kuisioner yang sudah tervalidasi sebagai instrument penelitian. Alat yang digunakan untuk penelitian ini adalah timbangan gantung dan timbangan berat badan yang sudah di kalibrasi untuk mengukur berat tas punggung. Data yang telah terkumpul diolah dengan menggunakan aplikasi Microsoft Word dan SPSS, kemudian disajikan dalam bentuk tabel.

\section{HASIL}

Karakteristik responden antar kelompok digambarkan dalam Tabel 1.

Tabel 2 menunjukkan karakteristik nyeri punggung terhadap perbedaan usia. Proporsi terbanyak nyeri punggung terdapat pada rentang usia 11 12 tahun, yaitu sejumlah 31 dari 33 orang (93.9\%).

Tabel 3 menunjukkan karakteristik nyeri punggung terhadap perbedaan tingkat pendidikan. Proporsi terbanyak nyeri punggung terdapat pada kelas 6 SD , yaitu sejumlah 19 dari 20 orang (95\%).

Tabel 4 menunjukkan karakteristik nyeri punggung terhadap perbedaan jenis kelamin. Proporsi 
Tabel 4 Karakteristik Subjek dengan Nyeri Punggung Berdasarkan Jenis Kelamin

\begin{tabular}{|c|c|c|c|c|}
\hline & & \multicolumn{2}{|c|}{ Keluhan nyeri punggung } & \multirow[b]{2}{*}{ Total } \\
\hline & & $\begin{array}{c}\text { Ada nyeri } \\
\text { N (\%) }\end{array}$ & $\begin{array}{c}\text { Tidak nyeri } \\
\text { N (\%) }\end{array}$ & \\
\hline \multirow[t]{2}{*}{ Jenis kelamin } & Perempuan & $25(92.6 \%)$ & $2(7.4 \%)$ & 27 \\
\hline & Laki-laki & $22(95.7 \%)$ & $1(4.3 \%)$ & 23 \\
\hline Total & & $47(94 \%)$ & $3(6 \%)$ & 50 \\
\hline
\end{tabular}

Tabel 5 Karakteristik Subjek dengan Nyeri Punggung Berdasarkan Berat Tas

\begin{tabular}{lcccc}
\hline & & \multicolumn{2}{c}{ Keluhan nyeri punggung } & \\
\cline { 3 - 4 } & & $\begin{array}{c}\text { Ada nyeri } \\
\mathbf{N}(\%)\end{array}$ & $\begin{array}{c}\text { Tidak nyeri } \\
\mathbf{N}(\%)\end{array}$ & Total \\
\hline \multirow{2}{*}{ Berat tas } & $<3 \mathrm{~kg}$ & $11(78.6 \%)$ & $3(21.4 \%)$ & 14 \\
& $>3 \mathrm{~kg}$ & $36(100 \%)$ & 0 & 36 \\
\multirow{2}{*}{ Total } & & $47(94 \%)$ & $3(6 \%)$ & 50 \\
\hline
\end{tabular}

Tabel 6 Uji Korelasi Nyeri Punggung dengan Penggunaan Tas Punggung

\begin{tabular}{lccccc}
\hline & & \multicolumn{2}{c}{ Nyeri Punggung } & & \\
\cline { 3 - 4 } Kelompok & $\begin{array}{c}\text { Ada nyeri } \\
\mathbf{N}(\%)\end{array}$ & $\begin{array}{c}\text { Tidak nyeri } \\
\mathbf{N}(\%)\end{array}$ & Total & P \\
\hline \multirow{2}{*}{ Berat tas } & $<3 \mathrm{~kg}$ & $11(78.6 \%)$ & $3(21.4 \%)$ & 14 & 0,004 \\
& $>3 \mathrm{~kg}$ & $36(100 \%)$ & 0 & 36 & \\
\hline
\end{tabular}

nyeri punggung pada kelompok perempuan, yaitu sejumlah 25 dari 27 orang (92.6\%), pada kelompok laki - laki sejumlah 22 dari 23 orang (95.7\%).

Tabel 5 menunjukkan karakteristik nyeri punggung terhadap perbedaan berat tas. Proporsi terbanyak nyeri punggung terdapat pada beban $>3 \mathrm{~kg}$, yaitu sejumlah 15 orang $(36 \%)$.

Untuk membuktikan hubungan nyeri punggung dengan penggunaan tas punggung digunakan uji korelasi Lambda. Terdapat 36 responden yang menggunakan tas punggung dengan berat diatas $3 \mathrm{~kg}$ dan 11 orang responden yang menggunakan tas punggung dengan berat dibawah $3 \mathrm{~kg}$ mengalami nyeri punggung. Setelah data dianalisis dengan uji korelasi Lambda, didapatkan nilai kemaknaan $\mathrm{p}=0.004$. Hasil penelitian ini adalah nilai ini menunjukkan adanya hubungan antara nyeri punggung dengan penggunaan tas punggung dengan berat $>3 \mathrm{~kg}$ (Tabel 6).

\section{DISKUSI}

Nyeri punggung adalah nyeri yang memiliki prevalensi kejadian $41,3 \%{ }^{4}$ Kejadian nyeri punggung disebabkan oleh beberapa faktor salah satunya adalah berat beban tas punggung yang digunakan. Tingkat pendidikan kelas empat, lima, dan enam menjadi variabel yang diteliti karena semakin tinggi tingkat pendidikan, maka semakin bertambah beban pelajaran dan semakin tebal buku pelajaran yang harus dibawa kesekolah setiap harinya.

Melalui hasil penelitian ini didapatkan bahwa siswa - siswi sekolah dasar di SDN 23 Dangin Puri Denpasar memiliki kejadian yang tinggi terhadap nyeri punggung dengan komorbiditas berat beban tas punggung sebanyak 94\%. Sedangkan 6\% nya tidak mengalami nyeri punggung. Siswa dengan berat tas lebih dari $3 \mathrm{~kg}$, sebanyak 36 (100\%) orang mengeluh nyeri punggung. Hal ini sesuai dengan penelitian Adi,dkk (2015), siswa dengan berat tas tas diatas $2,5 \mathrm{~kg}$ menderita nyeri punggung sebanyak $79,6 \%$ dibandingkan siswa dengan berat tas dibawah 2,5 kg sebanyak 20,4\%. ${ }^{5} \mathrm{Hal}$ ini diduga karena semakin berat beban pada tas punggung maka semakin menekan bagian punggung dari leher hingga punggung bawah, sesuai dengan hasil wawancara yang dilakukan yaitu hampir seluruh siswa yang beban tasnya diatas $3 \mathrm{~kg}$ mengeluhkan nyeri punggung.

Hubungan yang signifikan antara kedua variabel ini ditunjukkan dengan nilai $p=0,004(p<0,005)$. Hasil statistik yang signifikan menyatakan bahwa kejadian nyeri punggung dan berat tas punggung pada siswa siswi kelas 4,5,dan 6 di sekolah dasar dapat saling mempengaruhi satu sama lain. Hal ini didukung oleh beberapa penelitian mengenai hubungan nyeri punggung dan berat tas punggung yang digunakan.

Penelitian Jones et al (2004) sekitar 40,2\% anak usia 10-16 tahun mengalami nyeri punggung. ${ }^{6}$ penelitian Legiran (2010), pada 131 siswa kelas 4-6 di Sekolah Dasar Islam Terpadu Lukmanul Hakim Yogyakarta, menunjukkan bahwa sekitar 96 orang atau $73,3 \%$ mengalami nyeri punggung. ${ }^{7}$

Nyeri punggung yang dialami oleh siswa di SD 23 Dangin Puri Denpasar ini disebabkan karena mereka harus membawa semua buku pelajaran yang tidak sedikit. Namun, nyeri yang dirasakan bisa berkurang apabila diistirahatkan. Tas punggung yang berat tersebut dapat menarik otot otot di bagian leher sehingga menimbulkan nyeri pada bahu, kepala, leher, sampai nyeri punggung. Pada kondisi ini, beban yang diangkat berusaha mendorong tubuh untuk berlawanan dengan beban, sehingga untuk menahan beban tersebut serta menjaga keseimbangan tubuh, tubuh berusaha untuk bertumpu pada pinggul atau berusaha melengkungkan tulang punggungnya. Hal inilah yang menyebabkan anak merasakan sakit pada bahu, leher, dan punggungnya. ${ }^{8}$ 


\section{SIMPULAN}

Nyeri punggung pada siswa - siswi sekolah dasar di SDN 23 Dangin Puri Denpasar, lebih banyak terjadi pada usia 11 - 12 tahun (93.9\%), perempuan (92.6\%), dan di jenjang kelas 6 (95\%), berat tas $>3 \mathrm{~kg}(78.6 \%)$. Proporsi subjek penelitian yang mengalami nyeri punggung didapatkan sebesar $94 \%$. Nilai $\mathrm{p}=0,004(\mathrm{p}<0,005)$ menunjukkan bahwa terdapat hubungan bermakna antara penggunaan tas punggung dengan nyeri punggung.

\section{KONFLIK KEPENTINGAN}

Penulis menyatakan tidak terdapat suatu konflik kepentingan terhadap publikasi dari artikel ini.

\section{PENDANAAN}

Penelitian ini tidak mendapatkan suatu pendanaan yang diberikan oleh pemerintah ataupun lembaga swasta lainnya.

\section{KONTRIBUSI PENULIS}

Konsep penelitian: Kadek Puja Asmara Miranda, Sri Yenni Trisnawati, Ida Ayu Sri Wijayanti. Pengumpulan data, input data dan pengolahan data: Kadek Puja Asmara Miranda.Penyusunan naskah Penelitian: Kadek Puja Asmara Miranda.

\section{ETHICAL CLEARANCE NUMBER}

1667/UN14.2.2/PD/2018.

\section{DAFTAR PUSTAKA}

1. Avantika R., Shalini A. Back Problems Due to Heavy Backpacks in School Children. Research Scholar, Assistant Professor, Departement of Human Development \&Family Studies, School for Home Science Babashaheb Bhim Rao Ambedakar (A Central University) Lucknow India. 2013.

2. Sari K., Martadiani E., Asih M. Karakteristik temuan radiologis pada pasien low back pain di RSUP Sanglah Denpasar periode Maret 2016-Oktober 2017. Intisari Sains Medis. 2019. 10(1). DOI:10.15562/ism.v10i1.235.

3. Sara D., Med CS., Catherine B., Schoolbag Weight Limit: Can It Be Defined? American School Health Association (ASHA). 2013.

4. Faturachman, Rakha. Hubungan Antara Kebiasaan Menggunakan Tas Punggung Berat dan Kejadian Low Back Pain (LBP) pada Mahasiswa Program Studi Pendidikan Dokter FKIK UIN Syarif Hidayatullah Jakarta. Program Studi Pendidikan Dokter Fakultas Kedokteran dan Ilmu Kesehatan UIN Syarif Hidayatullah Jakarta. 2015.

5. Adiputra, Pradnya. Hubungan Berat Tas Punggung dengan Keluhan Nyeri Punggung Bawah, Nyeri Bahu, dan Nyeri Leher pada Siswa SD di Kecamatan Kuta, Badung. Program Studi Pendidikan Dokter Fakultas Kedokteran Universitas Udayana. 2017.

6. Jones G., Macfarlane G. Epidemiology of low back pain in children and adolescents. Arch Dis Child. 2005. 90: 312-316.

7. Legiran. Berat tas punggung dan prevalensi nyeri punggung pada siswa sekolah dasar. 2010. http://eprints.unsri. ac.id/207/3/Tas\%2520 Sekolah\%2520Artikel\%2520Penelit ian\%2 520Legiran.pdf.

8. Sya’bani, Purnima D. Hubungan Tingkat Pengetahuan Tentang Backpack Safety Terhadap Keluhan Nyeri Punggung pada Siswa Kelas 5 di Kelurahan TegalPanjang Garut. Fakultas Ilmu Keperawatan, Program Reguler 2008 Depok. 2012.

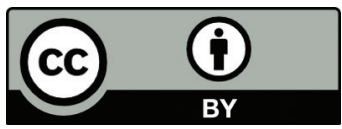

This work is licensed under a Creative Commons Attribution 